\title{
A COMBINATION OF SHEAR AND DYNAMIC COMPRESSION LEADS TO MECHANICALLY INDUCED CHONDROGENESIS OF HUMAN MESENCHYMAL STEM CELLS
}

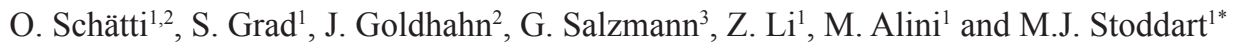 \\ ${ }^{1}$ AO Research Institute Davos, Clavadelerstrasse 8, Davos Platz, Switzerland \\ ${ }^{2}$ Institute for Biomechanics, ETH Zürich \\ ${ }^{3}$ Department Orthopädie and Traumatologie, Universitätsklinikum der Albert-Ludwigs-Universität, Freiburg, \\ Germany
}

\begin{abstract}
There is great interest in how bone marrow derived stem cells make fate decisions. Numerous studies have investigated the role of individual growth factors on mesenchymal stem cell differentiation, leading to protocols for cartilage, bone and adipose tissue. However, these protocols overlook the role of biomechanics on stem cell differentiation. There have been various studies that have applied mechanical stimulation to constructs containing mesenchymal stem cells, with varying degrees of success. One critical fate decision is that between cartilage and bone. Articular motion is a combination of compressive, tensile and shear deformations; therefore, one can presume that compression alone is unlikely to be a sufficient mechanical signal to generate a cartilage-like tissue in vitro. Within this study, we aimed to determine the role of shear on the fate of stem cell differentiation. Specifically, we investigated the potential enhancing effect of surface shear, superimposed on cyclic axial compression, on chondrogenic differentiation of human bone marrow-derived stem cells. Using a custom built loading device we applied compression, shear or a combination of both stimuli onto fibrin/polyurethane composites in which human mesenchymal stem cells were embedded, while no exogenous growth-factors were added to the culture medium. Both compression or shear alone was insufficient for the chondrogenic induction of human mesenchymal stem cells. However, the application of shear superimposed upon dynamic compression led to significant increases in chondrogenic gene expression. Histological analysis detected sulphated glycosaminoglycan and collagen II only in the compression and shear group. The results obtained may provide insight into post-operative care after cell therapy involving mesenchymal stromal cells.
\end{abstract}

Keywords: Chondrogenesis, mesenchymal stem cells, adult stem cells, differentiation, experimental models.

\author{
*Address for correspondence: \\ Martin J. Stoddart \\ Musculoskeletal Regeneration Program \\ AO Research Institute Davos \\ Clavadelerstrasse 8 \\ CH-7270 Davos Platz, Switzerland
}

Telephone Number: 0041-81-414-2448

FAX Number: 0041-84-414-2288

E-mail: martin.stoddart@aofoundation.org

\section{Introduction}

There is great interest in how bone marrow derived stem cells (MSCs) make fate decisions. One critical fate decision is that between cartilage and bone. Numerous studies have investigated the role of individual growth factors on mesenchymal stem cell differentiation, leading to protocols for cartilage, bone and adipose tissue. However, these protocols overlook the role of biomechanics on stem cell differentiation.

There have been various studies which have applied mechanical stimulation to constructs containing mesenchymal stem cells, with varying degrees of success. Comparison between the studies is often complicated due to variations in study protocol. Differences include age, species (bovine (Huang et al., 2010), porcine (Thorpe et al., 2008; Thorpe et al., 2010), and human (Miyanishi et al., 2006a; Li et al., 2009b; Kupcsik et al., 2010)), hydrogel component (agarose (Mauck et al., 2006; Huang et al., 2010) or fibrin (Li et al., 2009b; Li et al., 2009c; Kupcsik et al., 2010; Li et al., 2011)) and the actual loading protocol applied. Types of load applied have included hydrostatic (Angele et al., 2003; Miyanishi et al., 2006b; Wagner et al., 2008), uniaxial compression (Angele et al., 2004; Huang et al., 2004; Huang et al., 2005; Campbell et al., 2006) and multiaxial load (compression and shear combined) (Li et al., 2009b; Li et al., 2009c; Kupcsik et al., 2010; Li et al., 2011).

Articular motion is a combination of compressive, tensile and shear deformations; therefore, one can presume that compression alone is unlikely to be a sufficient mechanical signal to generate a cartilage-like tissue in vitro. Additional surface motion can produce shear forces and interfacial (articular) fluid flow at the surfaces of the contacting bodies. The advantage of multi-axial loading compared to uniaxial loading, in terms of chondrogenic gene expression, has already been documented in chondrocytes (Grad et al., 2006b). Moreover, complex loading has led to chondrogenic differentiation (Li et al., 2009b; Li et al., 2009c). Nonetheless, the exact mechanical stimuli that optimally promote chondrogenesis of MSCs are still unknown.

In this study, we aimed to determine the enhancing effect of the combination of cyclic axial compression with surface shear on chondrogenic differentiation of human bone marrow-derived stem cells. Surface shear is thought to enhance articular fluid flow as a mechanical input as well as nutrition and waste transport. A previously developed fibrin-polyurethane scaffold system is used to 


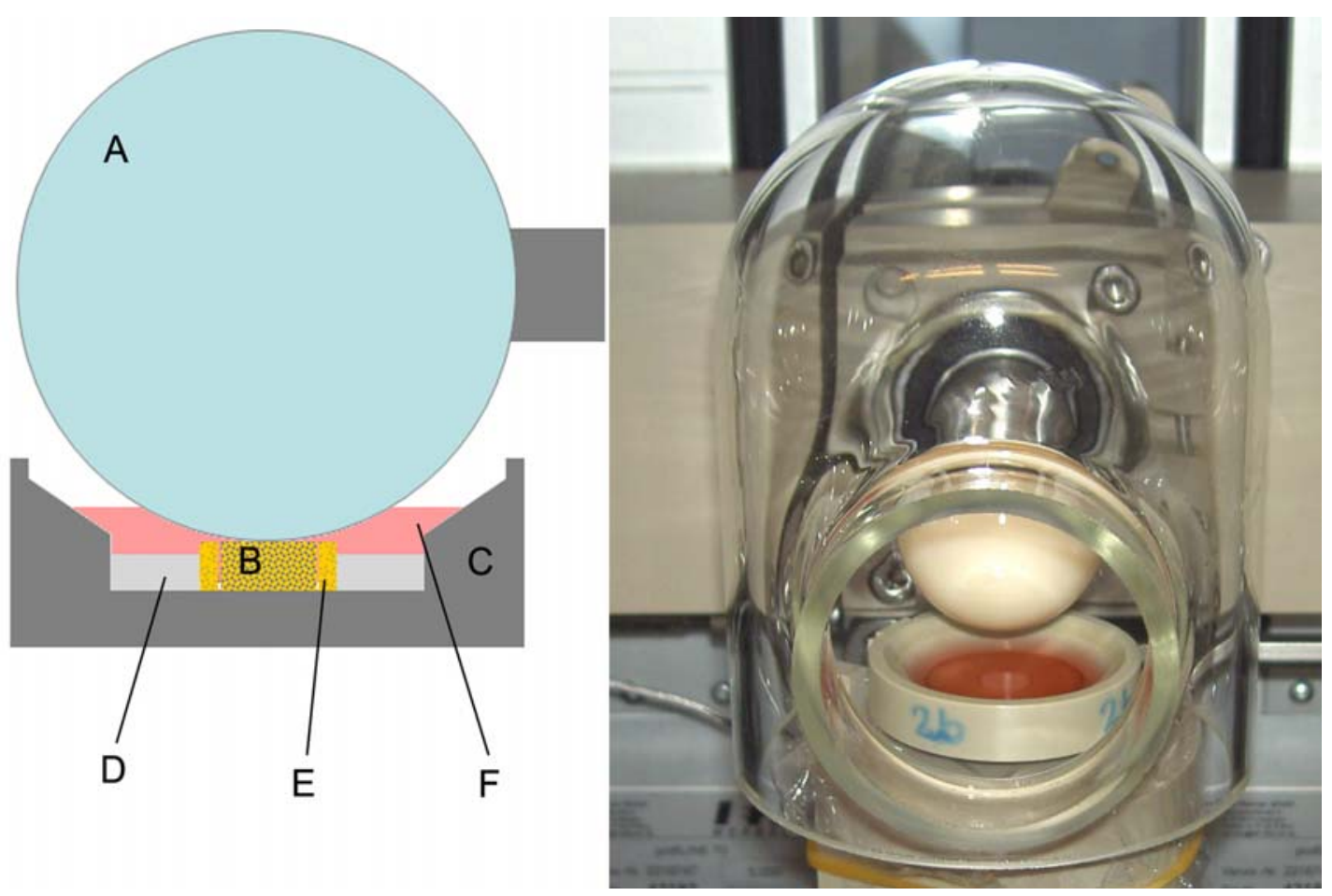

Fig. 1. Left: Cross sectional schematic of the scaffold with its holder. The ceramic hip ball (A) is pressed against the cell seeded scaffold (B). The scaffold (B) is held in place within the main holder (C) by means of a circular PEEK ring (D). A final ring of cell free fibrin/ PU scaffold (E) provides a final structural support to hold the sample in place. Right: Sample in holder. Both the sample and ball are housed in a glass bell to increase sterility.

give the cells an initial structure and a 3D guidance (Li et al., 2009a). To incorporate the interaction between cyclic compressive forces and shear forces, a custom-designed bioreactor system, which is capable of simultaneously applying compression and shear to a developing cellscaffold construct, is employed. Thus, we are able to approximate the kinematic motion of an articulating joint (Wimmer et al., 2004).

Using this custom built loading device, we applied compression, shear or a combination of both stimuli onto fibrin/polyurethane composites in which human mesenchymal stem cells were embedded. No exogenous growth-factors were added to the culture medium; therefore chondrogenic induction will be a direct result of the mechanical load applied. Using this experimental set-up we are able to directly compare the individual effects of axial compression, surface shear and the combination of the two stimuli. One major advantage of this device is the possibility to carry out reproducible multiaxial loading in vitro. This enables the work to be performed directly on human cells, and such studies would be difficult to reproducibly carry out in animal models. To determine the efficiency of chondrogenesis, chondrogenic, hypertrophic and osteoblastic gene expression levels were measured. The extra-cellular matrix (ECM) production was assessed in terms of synthesised glycosaminoglycan (GAG), histology and immunohistochemistry. We hypothesised that shear would be required for chondrogenic induction in the absence of exogenous chondrogenic stimuli.

\section{Materials and Methods}

\section{Isolation and expansion of human mesenchymal stem cells}

Fresh human bone-marrow aspirates were obtained after full ethical approval (Freiburg, EK-326/08) and informed patient consent. Bone marrow stromal cells were isolated from 5 donors (Male 17 years, Male 55 years, Female 70 years, Male 45 years, Female 66 years) by standard density gradient procedure (Histopaque-1077) and selection by plastic adherence. Mesenchymal stromal cells (MSCs) were then cultured in polystyrene cell culture flasks at 37 ${ }^{\circ} \mathrm{C}, 5 \% \mathrm{CO}_{2}$, and $95 \%$ humidity in $\alpha$-modified essential medium $(\alpha$-MEM), $10 \%$ human MSC qualified foetal bovine serum (FBS- Hyclone) with $5 \mathrm{ng} / \mathrm{mL}$ fibroblast growth factor 2 (Fitzgerald Industries, Acton, MA, USA). The cells were detached with Trypsin-EDTA at subconfluence and seeded into the required number of flasks. Thereafter, the medium was changed every 2-3 d. After the cells reached 70-80\% confluence, they were harvested and used for the experiment at passage 3-4. Each experiment was performed separately on each donor and the data collated for statistics.

\section{Fibrin-polyurethane composite culture of MSCs}

Cylindrical ( $8 \mathrm{~mm}$ diameter $\mathrm{x} 4 \mathrm{~mm}$ height) porous polyurethane scaffolds (pore size of 90-300 $\mu \mathrm{m}$ ) were prepared as described elsewhere (Gorna and Gogolewski, 2002). MSCs were suspended in a fibrin hydrogel (provided 
Table 1: Experimental groups

\begin{tabular}{|c|c|c|c|c|c|}
\hline \multirow[b]{2}{*}{ Experimental group } & \multicolumn{2}{|c|}{ Compression } & \multicolumn{2}{|c|}{ Shear } & \multirow[b]{2}{*}{$\begin{array}{l}\text { Preload } \\
\text { (height) }\end{array}$} \\
\hline & Frequency & $\begin{array}{c}\text { Amplitude } \\
\text { (height) }\end{array}$ & Frequency & Amplitude & \\
\hline Free swelling (A) & - & - & - & - & - \\
\hline Compression (B) & $1 \mathrm{~Hz}$ & $0.4 \mathrm{~mm}$ & - & - & $0.4 \mathrm{~mm}$ \\
\hline Shear $(\mathrm{C})$ & - & - & $1 \mathrm{~Hz}$ & $\pm 25^{\circ}$ & $0.4 \mathrm{~mm}$ \\
\hline Compression and shear (D) & $1 \mathrm{~Hz}$ & $0.4 \mathrm{~mm}$ & $1 \mathrm{~Hz}$ & $\pm 25^{\circ}$ & $0.4 \mathrm{~mm}$ \\
\hline
\end{tabular}

by Baxter BioScience, Vienna, Austria) before seeding them into the scaffolds. The final concentrations of the fibrin gel were $17 \mathrm{mg} / \mathrm{mL}$ fibrinogen and $0.5 \mathrm{U} / \mathrm{mL}$ of thrombin (Lee et al., 2005). Cells were seeded into the polyurethane scaffolds at a cell density of $4 \times 10^{6}$ per scaffold. Constructs were then incubated for $1 \mathrm{~h}$ at $37^{\circ} \mathrm{C}$, $5 \% \mathrm{CO}_{2}$ and $95 \%$ humidity to permit fibrin gel formation before adding growth medium (Dulbecco's Minimal Essential Medium, DMEM, with $4.5 \mathrm{~g} / \mathrm{L}$ glucose and $2.2 \mathrm{~g} / \mathrm{L} \mathrm{NaHCO}_{3}$, non-essential amino acids, containing $11.5 \mathrm{mg} / \mathrm{L}$ L-proline (Invitrogen/Life Technologies, Carlsbad, CA, USA), $50 \mu \mathrm{g} / \mathrm{mL}$ ascorbic acid 2-phosphate sesquimagnesium salt hydrate (Sigma-Aldrich, Buchs $\mathrm{SG}$, Switzerland), ITS $+1(10 \mu \mathrm{g} / \mathrm{mL}$ insulin from bovine pancreas, $5.5 \mu \mathrm{g} / \mathrm{mL}$ human transferrin (substantially iron-free), $5 \mathrm{ng} / \mathrm{mL}$ sodium selenite, $0.5 \mathrm{mg} / \mathrm{mL}$ bovine serum albumin and $4.7 \mu \mathrm{g} / \mathrm{mL}$ linoleic acid; SigmaAldrich), $100 \mathrm{U} / \mathrm{mL}$ penicillin $+100 \mu \mathrm{g} / \mathrm{mL}$ streptomycin (Invitrogen)). Five $\mu \mathrm{M} \varepsilon$-aminocaproic acid was added to inhibit fibrinolysis (Kupcsik et al., 2009). After 2-4 d of pre-culture in 12-well plates, cell-scaffold constructs were transferred in polyether ether ketone (PEEK) holders (Fig. 1). The experiments were carried out at $37{ }^{\circ} \mathrm{C}, 5 \% \mathrm{CO}_{2}$, $95 \%$ humidity. Medium was changed 3 times a week and collected for further analysis.

\section{Bioreactor}

Mechanical conditioning of the cell-scaffold constructs was performed using a pin-on-ball bioreactor system. Briefly, a ceramic ball $32 \mathrm{~mm}$ in diameter was pressed onto the scaffold (Wimmer et al., 2004). Interface shear motion was generated by oscillation of the ball about an axis perpendicular to the scaffold axis. Superimposed compressive strain was applied along the cylindrical axis of the scaffold.

Samples were assigned in quadruplicates to one of four groups (Table 1): Group A was the free-swelling (unloaded) control. Group B was exposed to unconfined dynamic compression at $1 \mathrm{~Hz}$ with $0.4 \mathrm{~mm}$ sinusoidal strain, superimposed on a $0.4 \mathrm{~mm}$ static offset strain, resulting in a strain amplitude of $10-20 \%$ of the scaffold height at the centre of the construct. Group $\mathrm{C}$ was exposed to ball oscillation of $\pm 25^{\circ}$ at $1 \mathrm{~Hz}$, superimposed on a $0.4 \mathrm{~mm}$ static compression offset strain. Group D was a combination of both loading regimes. Mechanical load was applied during $1 \mathrm{~h}$ a day for 5 consecutive days per week over 3 weeks.

\section{Analysis}

After 3 weeks of culture and 15 loading cycles, cellscaffold constructs were vertically cut in two halves; 3 scaffold halves were processed for biochemical analysis, 3 for gene expression analysis and 2 for histological and immunohistochemical analysis.

\section{Gene expression}

Scaffolds used for gene expression analysis were homogenised in $1 \mathrm{~mL}$ TRI reagent and $5 \mu \mathrm{L}$ Polyacryl Carrier (both Molecular Research Center, Cincinnati, OH, USA) per scaffold, using a Tissue-Lyser (Retsch \& Co., Haan, Germany) and centrifuged (Eppendorf, Basel, Switzerland) at $4{ }^{\circ} \mathrm{C}$ for $10 \mathrm{~min}$ at $12000 \mathrm{~g}$.

RNA isolation was carried out according to the protocol from the manufacturer. RNA was reverse transcribed with TaqMan reverse transcription kit (Applied Biosystems, Foster City, CA, USA) using random hexamers. For real time PCR TaqMan Gene Expression Assays (Applied Biosystems) or custom designed primer-probe sets (from Microsynth, Balgach, Switzerland) were used on a GeneAmp 7500 Real Time PCR System (Applied Biosystems). The endogenous control gene was $18 \mathrm{~S}$ rRNA. Chondrogenic markers (collagen type-II ( $\mathrm{Col} 2)$, Aggrecan (AGG), cartilage oligomeric matrix protein (COMP), SRY (sex determining region $\mathrm{Y}$ ) - box 9 (Sox9), proteoglycan-4 (PRG4)), osteogenic markers (collagen type-I (Col 1), alkaline phosphatase (ALP)) and hypertrophic markers (collagen type-X (Col 10)) were analysed. Gene expression was analysed according to the ${ }^{\Delta \Delta} \mathrm{Ct}$ method, with expression levels normalised to the corresponding day 0 sample (day of cell seeding into scaffolds) of each donor.

The primers and probes used are listed in Table 2.

\section{Biochemical analysis}

Scaffolds used for biochemical analysis were digested with $0.5 \mathrm{mg} / \mathrm{mL}$ proteinase $\mathrm{K}$ at $56{ }^{\circ} \mathrm{C}$ overnight and used for DNA and glycosaminoglycan (GAG) measurement.

DNA concentrations were determined with the Hoechst method using calfDNA as a standard (Labarca and Paigen, 1980). Fluorescence intensity was measured with an HTS 7000 Perkin Elmer Bio Assay Reader (Norwalk, CT, USA).

The amount of glycosaminoglycan (GAG) was determined by the dimethylmethylene blue dye method, using bovine chondroitin sulphate as the standard (Farndale et al., 1986). Proteinase K digests were used to measure 
Table 2: Primer/Probes (fw: forward; rev: reverse)

\begin{tabular}{|c|c|c|c|c|}
\hline Gene & Abbr. & $\begin{array}{l}\text { Primer fw 5' - } \\
\text { 3' }\end{array}$ & $\begin{array}{l}\text { Primer rev 5' - } \\
\text { 3' }\end{array}$ & $\begin{array}{l}\text { Probe (5'FAM } \\
\text { / 3'TAMRA) } \\
\end{array}$ \\
\hline Collagen type I $\alpha 1$ chain & Col 1 & $\begin{array}{l}\text { CCC TGG AAA GAA } \\
\text { TGG AGA TGA T }\end{array}$ & $\begin{array}{l}\text { ACT GAA ACC TCT } \\
\text { GTG TCC CTT CA }\end{array}$ & $\begin{array}{l}\text { CGG GCA ATC CTC } \\
\text { GAG CAC CCT }\end{array}$ \\
\hline Collagen type II $\alpha 1$ chain & $\mathrm{Col} 2$ & $\begin{array}{l}\text { GGC AAT AGC AGG } \\
\text { TTC ACG TAC A }\end{array}$ & $\begin{array}{l}\text { GAT AAC AGT CTT GCC } \\
\text { CCA CTT ACC }\end{array}$ & $\begin{array}{l}\text { CCT GAA GGA TGG } \\
\text { CTG CAC GAA ACA } \\
\text { TAC }\end{array}$ \\
\hline Collagen type $\mathrm{X} \alpha 1$ chain & Col 10 & $\begin{array}{l}\text { ACG CTG AAC GAT } \\
\text { ACC AAA TG }\end{array}$ & $\begin{array}{l}\text { TGC TAT ACC TTT ACT } \\
\text { CTT TAT GGT GTA }\end{array}$ & $\begin{array}{l}\text { ACT ACC CAA CAC } \\
\text { CAA GAC ACA GTT } \\
\text { CTT CAT TCC }\end{array}$ \\
\hline Aggrecan & AGG & $\begin{array}{l}\text { AGT CCT CAA GCC } \\
\text { TCC TGT ACT CA }\end{array}$ & $\begin{array}{l}\text { CGG GAA GTG GCG } \\
\text { GTA ACA }\end{array}$ & $\begin{array}{l}\text { CCG GAA TGG AAA } \\
\text { CGT GAA TCA GAA } \\
\text { TCA ACT }\end{array}$ \\
\hline Proteoglycan-4 & PRG4 & $\begin{array}{l}\text { GAG TAC CCA ATC } \\
\text { AAG GCA TTA TCA }\end{array}$ & $\begin{array}{l}\text { CCA TCT ACT GGC TTA } \\
\text { CCA TTG CA }\end{array}$ & $\begin{array}{l}\text { CAA TCC CAT GCT } \\
\text { TTC CGA TGA GAC } \\
\text { CAA T }\end{array}$ \\
\hline Gene & Abbr. & \multicolumn{3}{|c|}{ Applied Biosystems Serial number } \\
\hline $\begin{array}{l}\text { Cartilage Oligomeric } \\
\text { Matrix Protein }\end{array}$ & COMP & \multicolumn{3}{|l|}{ Hs_00164359_m1 } \\
\hline $\begin{array}{l}\text { SRY (sex determining } \\
\text { region } Y \text { ) - box } 9\end{array}$ & Sox 9 & \multicolumn{3}{|l|}{ Hs_00165814_m1 } \\
\hline $\begin{array}{l}\text { Alkaline Phosphatase, } \\
\text { liver/bone/kidney }\end{array}$ & ALP & \multicolumn{3}{|l|}{ Hs_00758162_m1 } \\
\hline 18S rRNA & $18 \mathrm{~S}$ & \multicolumn{3}{|l|}{$4310893 \mathrm{E}$} \\
\hline
\end{tabular}

the GAG content of the scaffolds. The total GAG content of the culture media, collected at each media change, was also measured to assess the release of matrix molecules from the sample into the media. Absorbance was measured with a Victor3 Perkin Elmer (Waltham, MA, USA) 1420 multilabel counter. GAG values were normalised to the DNA content.

\section{Histology and immunohistochemistry}

For immunohistochemical analysis scaffolds were fixed in $70 \%$ methanol at $4{ }^{\circ} \mathrm{C}$ and incubated in $5 \% \mathrm{D}(+)$ sucrose solution in phosphate buffered saline (PBS) for $12 \mathrm{~h}$ at $4{ }^{\circ} \mathrm{C}$ before embedding them in Jung tissue freezing compound and cryosectioning at $10 \mu \mathrm{m}$ (Microm HM560 CryoStar, Thermo Scientific, Waltham, MA, USA). To visualise cell distribution and extracellular matrix accumulation sections were stained with Toluidine Blue. The deposition of collagen types I and II, and aggrecan was determined by immunohistochemistry.

After enzyme pre-treatment $(0.25 \mathrm{U} / \mathrm{mL}$ Chondroitinase $\mathrm{AC}$ for aggrecan and $0.5 \mathrm{U} / \mathrm{mL}$ Hyaluronidase for collagen types I and II staining (both Sigma-Aldrich,)), sections were blocked with $5 \%$ horse serum. Then sections were incubated using primary antibodies raised against Col 1 (Col I, 1:2000 dilution), Col 2 (CIICI, 1:6 dilution) and
AGG (1-C-6, 1:5 dilution). The antibody against type I collagen was from Sigma (Sigma-Aldrich). Collagen type II and aggrecan antibodies were from Development Studies Hybridoma Bank (DSHB, University of Iowa, Iowa City, IA, USA). Before detection of aggrecan, a neo-epitope had to be generated by reduction and alkylation steps. Primary antibody was applied overnight at $4{ }^{\circ} \mathrm{C}$ for collagen type $\mathrm{I}$ and II, and for $30 \mathrm{~min}$ at room temperature (RT) for aggrecan. This was followed by biotinylated secondary antibody (30 min, RT) and the preformed avidin-biotinperoxidase complex (30 min, RT) from Vectastain ABC Kit (Vector Laboratories, Burlingame, CA, USA). As a chromogen, 3, 3'-diaminobenzidine monomer (DAB) was used. For the negative control, the primary antibody was replaced by PBS. Between each step, sections were washed with $5 \%$ Tween 20 in PBS. Sections were counterstained with Meyer's Haematoxylin for $15 \mathrm{~s}$, cleared in xylene and coverslipped with DPX.

\section{Statistical analysis}

Statistical analysis was performed using the software package SPSS (Version 18, SPSS Inc, Chigaco, IL, USA). Data were analysed using a general linear model with repeated measures. The significance level was defined at $p$ $<0.05$. For the post hoc, $p$-values were adjusted according 


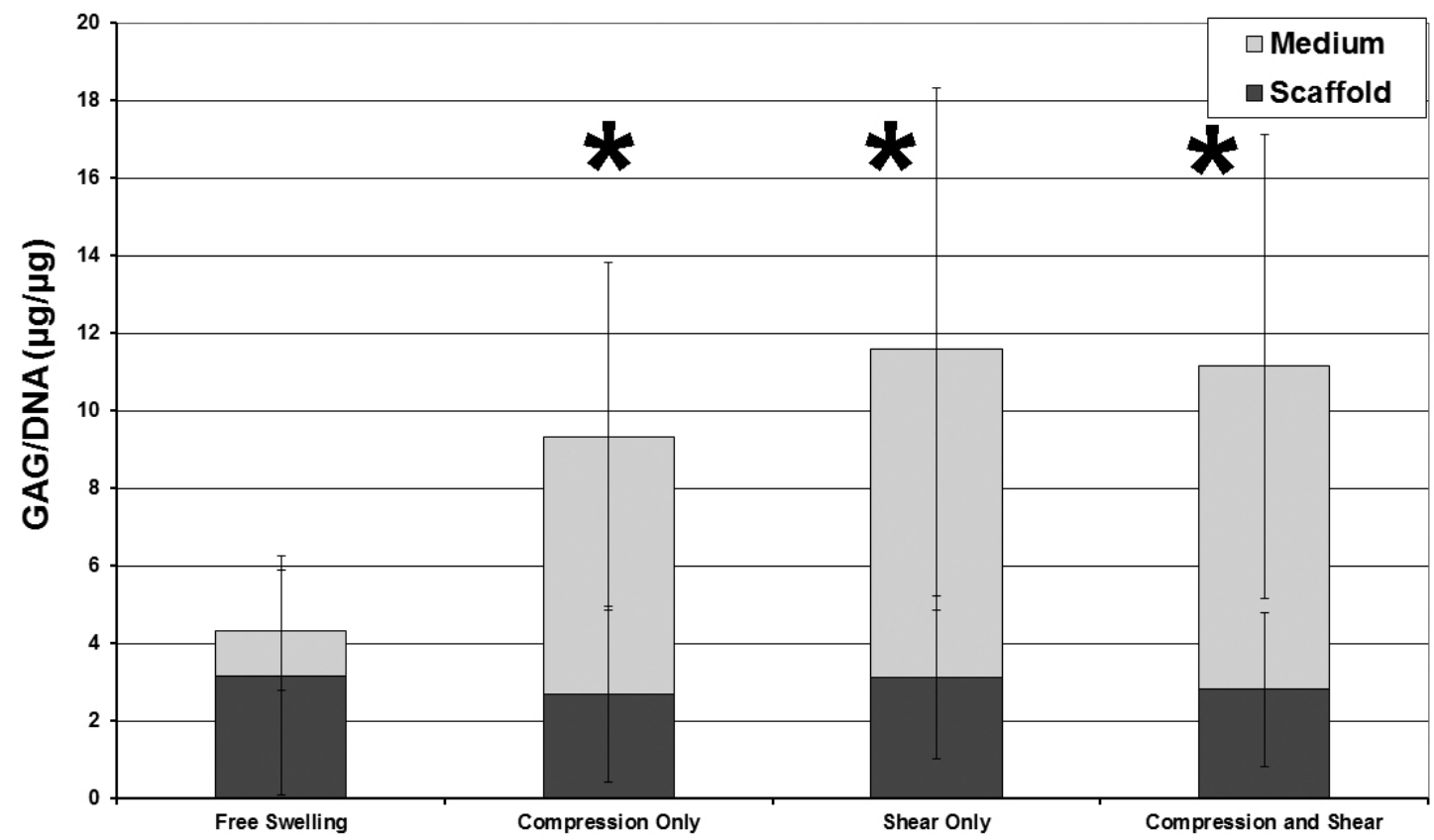

Fig. 2. Total GAG/DNA contained within the scaffold and the medium after 21 days of cultivation. $*=p<0.05$ relative to unloaded control.

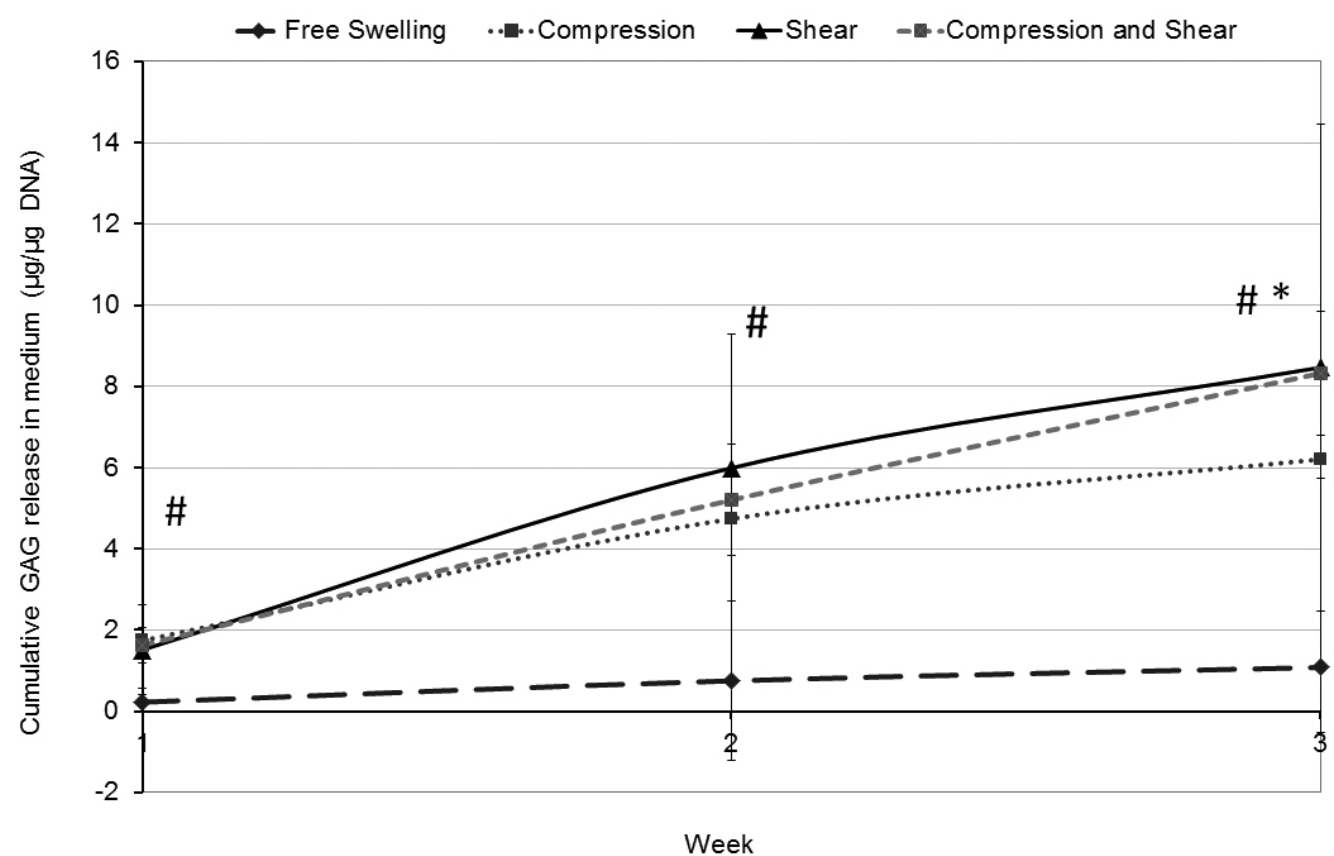

Fig. 3. Accumulated GAG released into medium over three weeks of culture. Compression alone shows a trend towards a plateau of secretion. $\# p<0.05$ relative to free swelling, $*=p<0.05$ relative to compression alone.

to Bonferroni's method. Five experiments, each with a different donor, were run in triplicates for gene expression and biochemical analyses.

\section{Results}

\section{Biochemical analysis}

There was no difference in the DNA content between the groups (data not shown). Total GAG synthesised (scaffolds plus medium) was normalised to DNA for each scaffold. The amount of GAG per DNA (Fig. 2) was significantly higher in all loaded groups over control (Compression $p \leq$ 0.05 , Shear, compression and shear $p \leq 0.01$ ). There was a trend towards higher total GAG/DNA values in the loaded groups which included shear, but no significant difference over the compression only group was detected. All individual donors demonstrated the same trend. Between the loaded groups, there was a trend visible towards higher retention of GAG in the scaffolds with shear. 
a

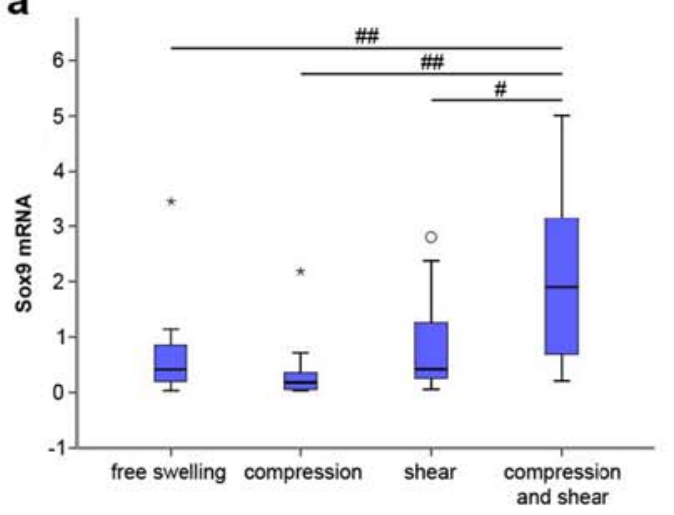

C

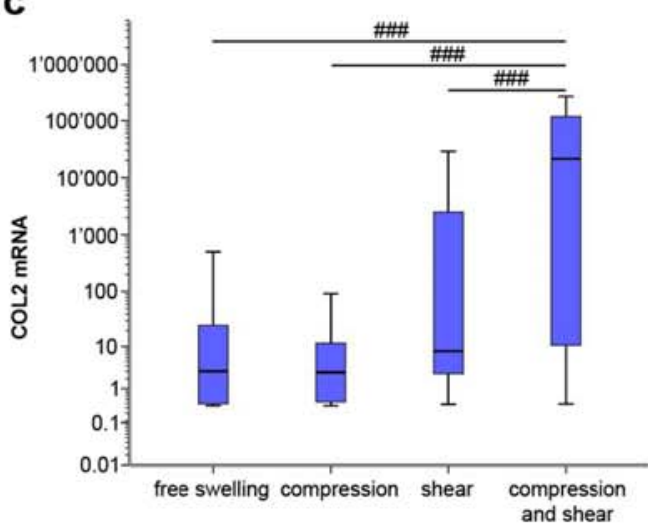

e

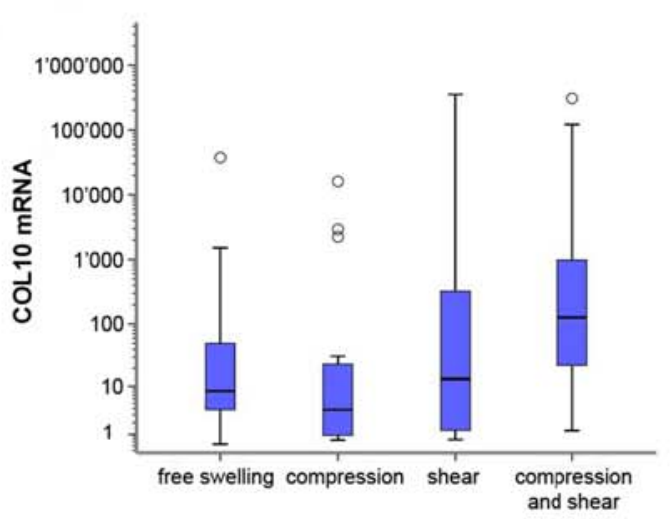

g

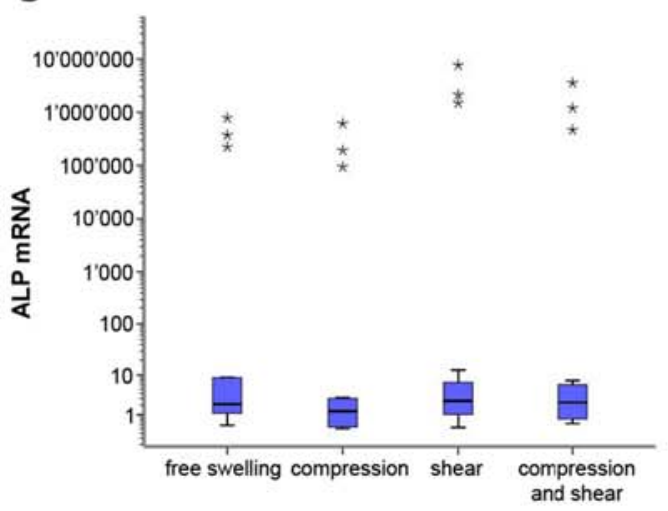

b

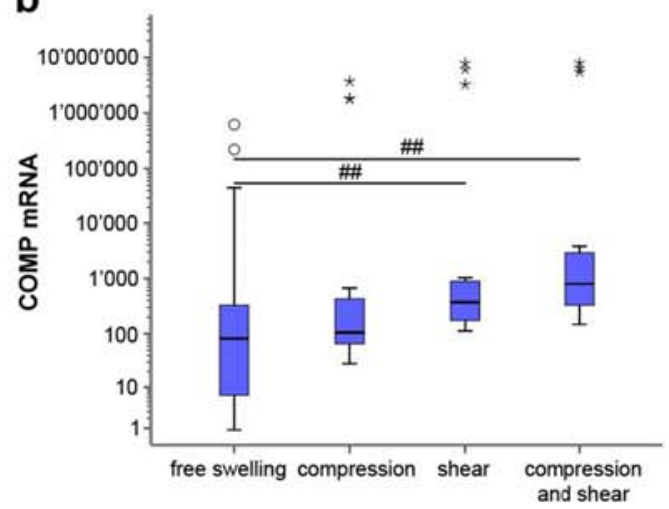

d

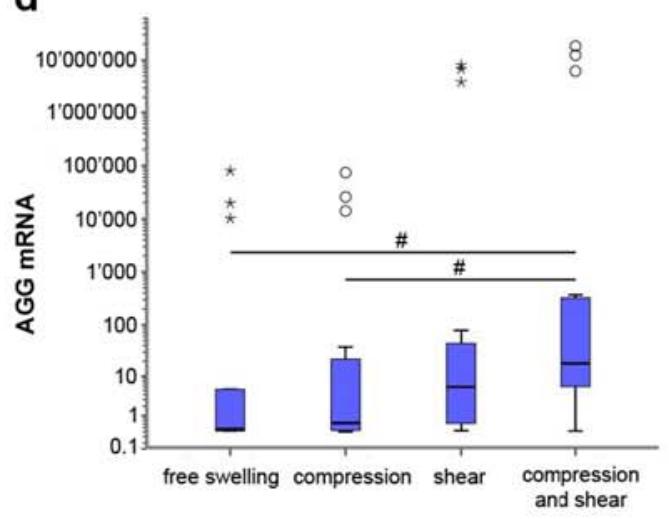

f

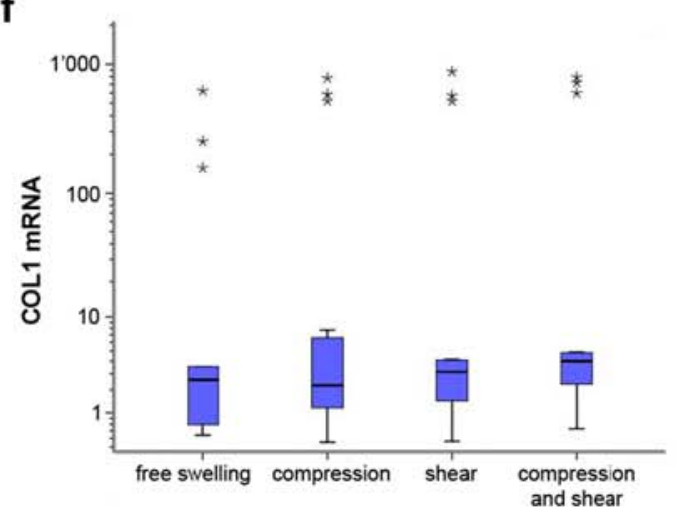

Fig. 4. Relative mRNA expression of human mesenchymal stem cells after 21 days. 4 different experimental groups: Free swelling, Compression, Shear, and Compression and shear. All data were normalized to day 0 values. $n=5$ (triplicates per group). \# $p<0.05$, \#\# $p<0.01$, \#\#\# $p<0.001$. 

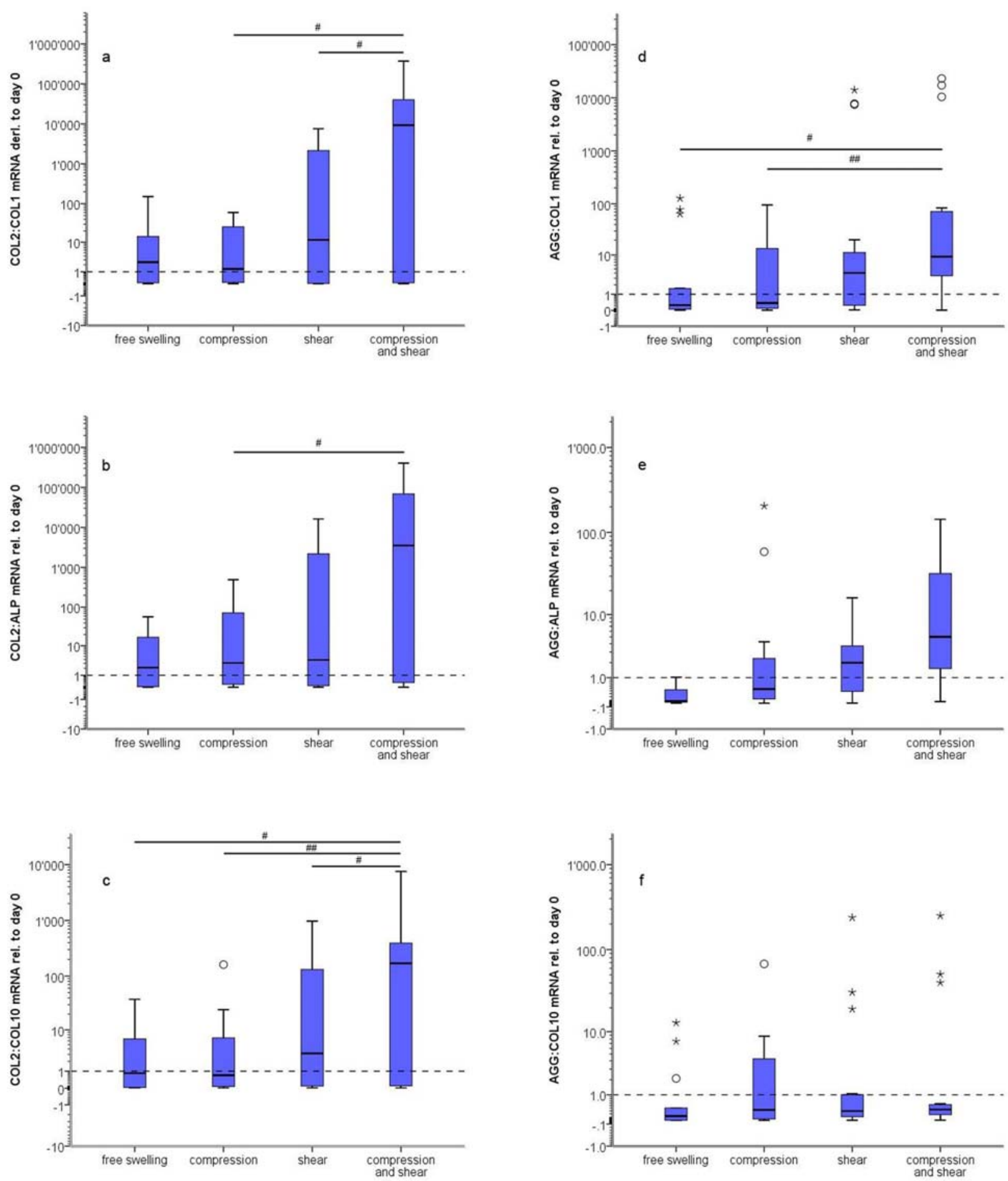

Fig. 5. Different phenotypic gene expression ratios of human bone marrow mesenchymal stem cells-seeded scaffolds after 21 days of culture. (a) Col2:Col1, (b) Col2:ALP, (c) Col2:Col10, (d) AGG:Col1, (e) AGG:ALP and (f) AGG:Col10. All data were normalised to day 0 values. $n=5$ (triplicates per group). $\# p \leq 0.05$, \#\# $p \leq 0.01$.

The average amounts of GAG secreted in to medium for each week of the culture phase are displayed in Fig. 3. Similar to Fig. 2, where total GAG is displayed, the loaded groups showed also higher GAG values in the medium at all three timepoints. In week 1 , a significant difference in GAG released into the medium $(p \leq 0.05)$ was detected between compression alone and compression and shear compared to free swelling. No significant difference between loaded groups was observed for week 2. By week 3, compression and shear, and shear alone had a significantly $(p \leq 0.05)$ higher value of GAG which is released into the culture medium compared to the other experimental groups indicating a higher production.

\section{Gene expression analysis}

Gene expression was dependent on the loading regime applied. Compared to the mRNA levels of Group A, Group $\mathrm{B}$ did not show a significant effect on mRNA expression of 

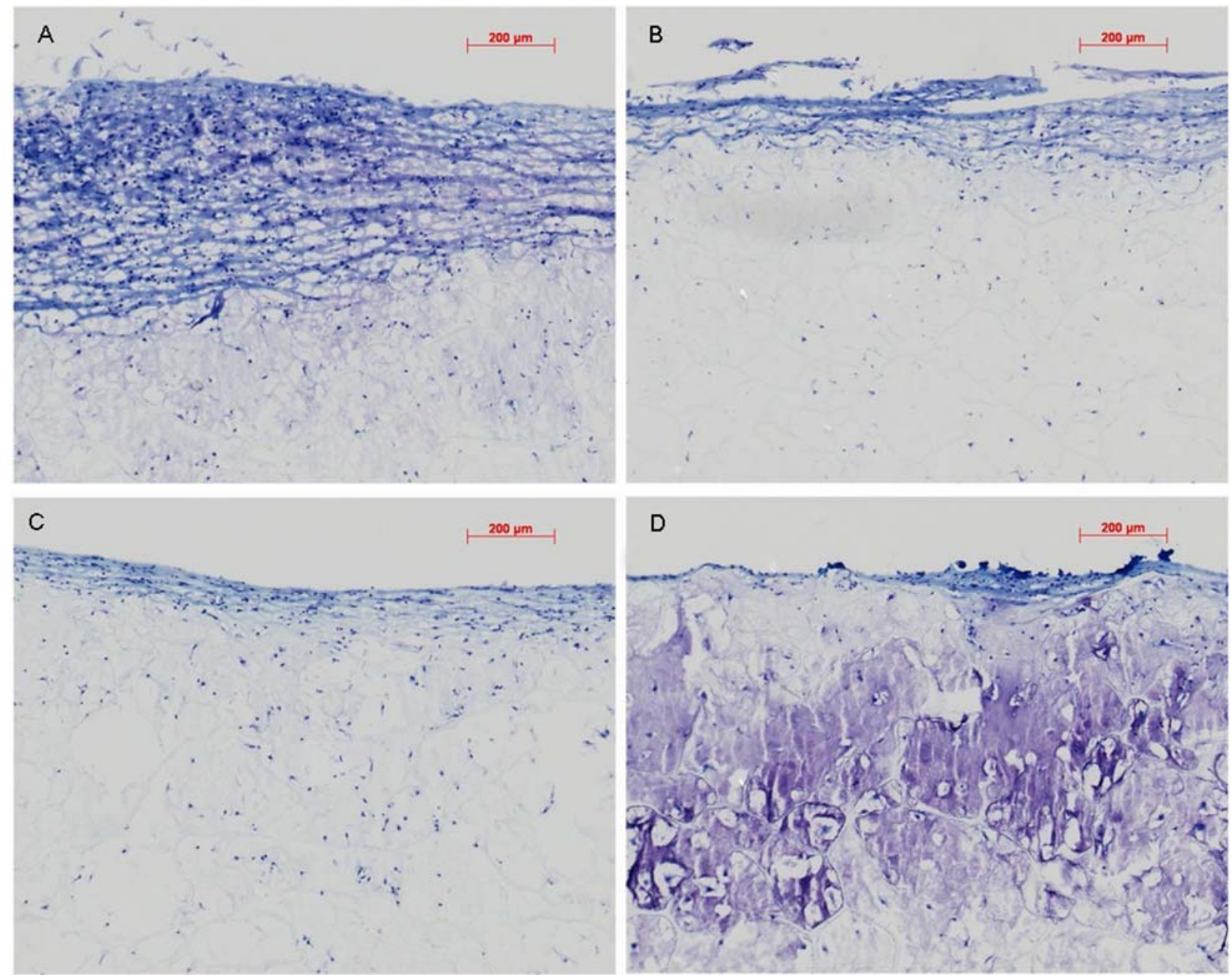

Fig. 6. Representative toluidine blue cryo-sections after different loading regimes applied on cell- seeded fibrinpolyurethane scaffolds (donor Male 55 years). Scale bar $=200 \mu \mathrm{m}$. Free-swelling (a), Compression (b), shear (c), and compression and shear (d).

the genes analysed (Fig. 4). Group C showed a significant up-regulation for the COMP gene. However, exposure to a sliding motion, superimposed on mechanical compression (Group D), led to a significant up-regulation of Sox9, Col 2, AGG and COMP. Multiaxial loading (Group D) showed a significant $(p \leq 0.01)$ up-regulation of Sox9 mRNA compared to uniaxial loaded groups as well as the free swelling control. An even greater effect $(p \leq 0.001)$ was observed for Col 2 mRNA expression in Group D. Similar output was observable for COMP and AGG mRNA upregulation. The combination of compression and shear led to a significantly $(p \leq 0.05)$ increased gene expression of AGG compared to compression or free swelling and compared to free swelling in COMP. No significant difference in the gene expression of Col 1, Col 10, ALP and PRG4 could be detected between groups.

For COMP, AGG, Col 10, Col 1 and ALP a distinct set of outliers can be seen. These data points came from the same donor (Male 17 years). While the magnitude is much greater than in the main group, the relative trend is identical.

\section{Gene expression ratios}

Compared to day 0 samples, mechanical intervention had a beneficial effect on the chondrogenesis of cells, as indicated by all ratios higher than 1 (Fig. 5). Significant differences in favour of the chondrogenic markers were found for the Col2:Col1, Col2:ALP, Col2:Col10 and AGG:Col1 ratios. The Groups A and B show approximately the same ratio of around or slightly below 1 . The latter implies that in these experimental groups the hypertrophic (Col10) or the osteogenic (ALP, Col1) genes still predominate. However, when shear is incorporated into the loading protocol the chondrogenic ratio increases markedly. This effect is most pronounced when shear is combined with mechanical compression (Group D). A significantly elevated ratio was observed between compression and shear, and compression alone $(p \leq 0.01)$. In addition, significant differences were detected between Group A and Group D $(p \leq 0.05)$, as well as Group C and Group D ( $p \leq 0.05)$. Col2:Col1, Col2:ALP and AGG:Col1 showed a similar pattern with significantly $(p \leq 0.05)$ different ratios between Group B and Group D. Furthermore Col2:Col1 (between Group C and Group D) and AGG:Coll (between Group A and Group D) show significant $(p \leq 0.05)$ differences. 


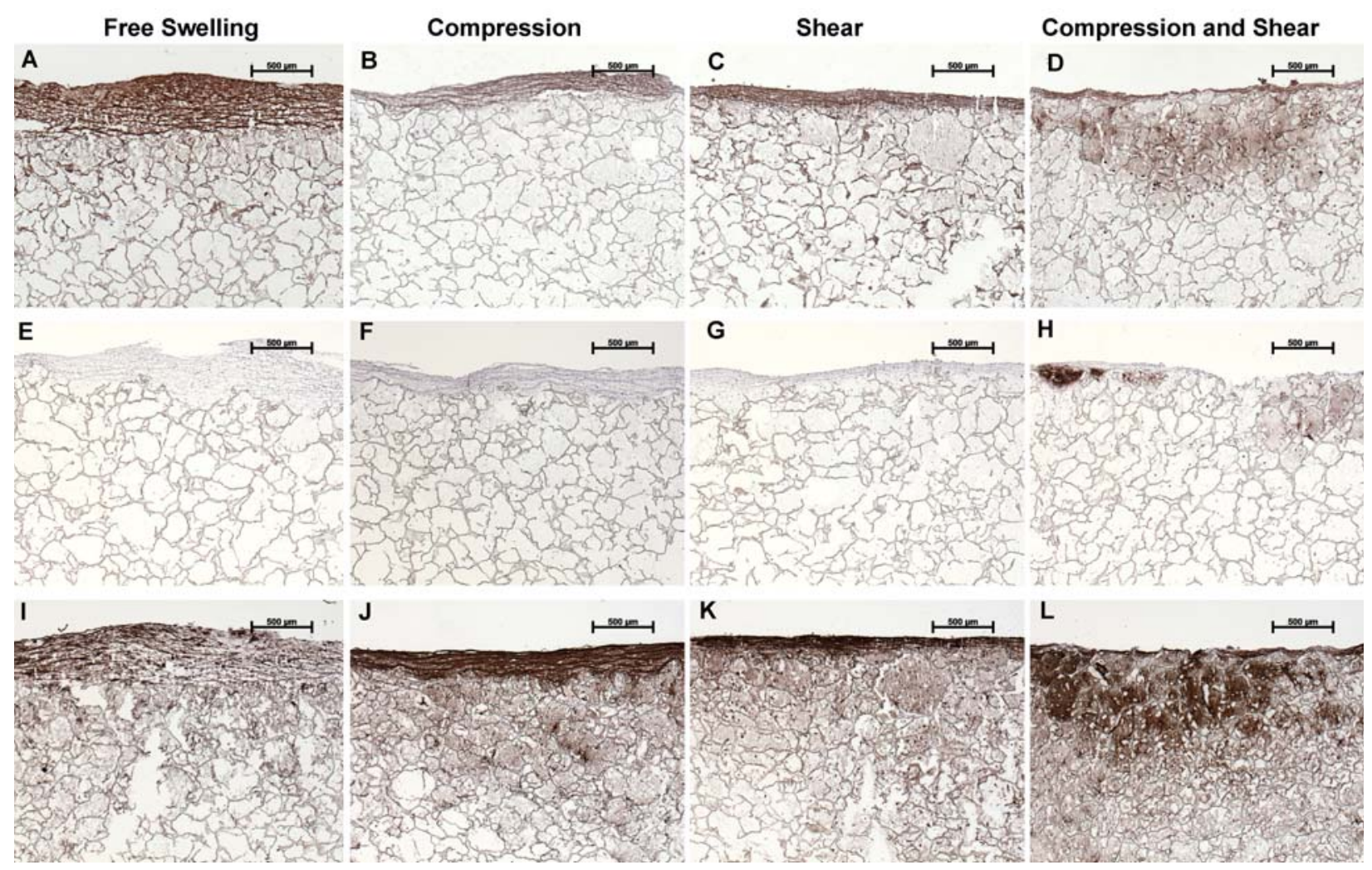

Fig. 7. Representative cryo-sections after different loading regimes (donor Male 45 years). Agg (A-D), Col 2 (E-H), Col 1 (I-L); from left to right: free swelling (Group A), compression (Group B), shear (Group C), compression and shear (Group D). The scale bar represents $500 \mu \mathrm{m}$. Total area $\sim 0.8 \mathrm{~cm}^{2}$.

\section{Histology and immunohistochemistry}

Sections of cell scaffold constructs were stained with Toluidine blue (Fig. 6). Generally the extra- cellular matrix (ECM) was more pronounced in the outer regions of the cell-seeded constructs, while the central regions of the scaffolds had fewer cells and less ECM. These findings were present throughout all loading groups. The surface of the constructs appeared smoother in Group C and Group D. Group A and Group B resulted in a more unorganised and fibro- cartilaginous surface. Furthermore, in Group A, the main accumulation of tissue appears to have occurred on top rather than within the scaffold. Accumulation of proteoglycan-rich ECM was only observed in constructs where compression and shear was applied as indicated by the metachromatic staining.

Immunostaining for $\mathrm{Col} 1, \mathrm{Col} 2$, and $\mathrm{AGG}$ is shown in Fig. 7. No obvious difference of Col 1 staining was observed between Group B and Group C. Both sections show a thick layer of the protein at the edge of the scaffolds and a weaker deposition towards the central regions. No clear layer on the surface and a more positive staining towards the central areas is visible in the multiaxial compression and shear group. Group A shows an evenly weak staining with some higher amount of Col 1 deposition on the uppermost layer of the scaffold.

No collagen type II staining was visible in any sections except for the group where compression and shear is combined. A slight staining can be observed on certain areas below the surface of the scaffold with a weak deposition of collagen type II in more central areas. Aggrecan deposition can be seen in all loading groups. The most evenly stained scaffolds can be found in Group D. Group B and Group C appear similar, with a more intense staining in Group C. Group A has unevenly distribution with a high cell accumulation on top of the scaffold. Negative control sections for all proteins showed no staining throughout all cell-seeded scaffold constructs in all groups (data not shown). As already implied in the toluidine blue staining, Group A contains a layer of fibrocartilaginous matrix on top of the scaffold surface.

\section{Discussion}

The aim of this study was to investigate the influence of mechanical load, in particular the potential of surface shear strain to act as a chondrogenic inducer for MSCs. Mechanical load is one of several factors which are known to affect chondrogenesis of MSCs. With more detailed information on different loading types we hope to develop a better insight into the mechano-sensing and -regulation of MSCs and, in a further step, a more deepened comprehension of chondrogenic induction, as well as preservation of the chondrogenic phenotype.

Previous studies have already demonstrated beneficial effects of surface shear on chondrocytes (Grad et al., 2006a). Studies incorporating shear showed an increased GAG production for the multiaxial loaded groups, an 
up-regulation of chondrogenic gene markers as well as the presence of cartilage-specific proteins. GAG content was also elevated in our study; similar to findings with chondrocytes, within the loaded groups there was a trend towards a greater GAG increase in the groups containing shear. We have previously shown that within this system the addition of $10 \mathrm{ng} / \mathrm{mL}$ TGF $\beta 1$ leads to a more robust chondrogenesis than that generated by mechanical induction, suggesting further improvements are possible (Li et al., 2010b). From a biochemical point of view, the production of GAG is an important parameter indicating chondrogenic differentiation. Once MSCs acquire a chondrogenic phenotype, the challenge is to prevent them from becoming hypertrophic. Amongst others, this step is associated with a decrease in GAG secretion. Looking at the time course of GAG secretion in the medium through all groups, the compression and shear group seems to maintain a constant release of GAG while in the other groups a decreased GAG release with time can be observed. This suggests that with combined loading of compression and shear, GAG production does not decrease and the chondrogenic phenotype is more likely to be preserved than with the uniaxial loading groups or the free swelling control but this would have to be confirmed with further studies.

Generally, gene expression was dependent on the loading regime and significant differences between the experimental groups could be detected. In this study, the incorporation of shear into the loading protocol showed increased chondrogenic gene markers. However, hypertrophic (Col 10) and osteogenic (Col 1 and ALP) gene markers were not affected by surface shear. This is highly favourable, showing that compression and shear may lead to a more stable chondrogenic phenotype. Thus, cultured cells are less likely to become hypertrophic and more likely to refrain from progressing towards bone. Most importantly, only samples loaded with compression and shear showed a significant up-regulation of the chondrogenic gene markers Col 2, AGG, COMP, and Sox9, an important chondrogenic transcription factor.

While the mRNA expression of AGG in the compression alone and the shear alone groups was comparable to the unloaded control, this does not exclude the possibility that increases would have been detected if samples had been taken at earlier time points. All loaded groups had an increase in GAG/DNA, in some cases without an apparent increase in AGG expression, which suggests further investigation into the translation of mRNA into actual sulphated GAG is required.

Although there was a remarkable increase in Col 2 mRNA in the compression and shear group, only a slight deposition could be detected. There can be several reasons for this. First, Col 2 up-regulation on the protein level in MSCs is known to be very poor. Even under optimal medium composition, it can take several weeks, and one needs to consider that TGF- $\beta$, the most potent factor inducing chondrogenesis, is lacking in the culture medium. Second, as the matrix produced is relatively immature a large proportion is likely to have been released into the medium. This release was not investigated, which is one of the weaknesses of this study.
The gene expression data for COMP, AGG, Col 1, Col 10 and ALP shows a set of distinct outliers, some of them as much as 3 times the IQR. All these data points originate from the same donor and while the magnitude is different, the trends between the groups are identical to the main body of data. This dataset was obtained from a 17 year old donor, while the remaining 4 donors ranged from 45-70 years. This would suggest that younger donors are much more responsive on an mRNA level but more work would be required to confirm this. The question of whether the vitality and efficiency of human MSCs decrease with age is still unresolved; however the prevailing view is that both numbers and efficiency decrease with increasing age (Caplan, 2007). Our data would support that theory. It also would indicate that a chondrogenic response can still be induced in elderly cells, albeit to a lesser extent.

Gene expression ratios enable a direct comparison between the regulation of two different gene products. In this study, we evaluated whether a superior chondrogenic phenotype would be achieved with the integration of shear. All three ratios generated with Col 2 showed significantly enhanced chondrocyte-specific phenotype for the compression and shear loading group. The domination of Col 2 over Col 10 as well as Col 2:ALP, Col 2:Col 1, and AGG:Col 1 support the hypothesis that it is possible to provide a more stable chondrogenic phenotype with complex loading.

Cryosections stained with toluidine blue and by immunolabelling showed a similar pattern for the free swelling control group. Under free swelling condition, the cells appear to accumulate on top of the scaffold where also the build-up of the matrix takes place. Here, nutrients and oxygen are more available than within the scaffold. From the immunohistochemical staining, it is apparent that mainly Col 1 is being produced. Comparing the uniaxially loaded samples, the smoother surface of the shear group becomes obvious. Articular cartilage requires a smooth and nearly frictionless surface to optimally meet the mechanical demands. The metachromatic stain displayed in the compression and shear group indicates a superior development of sulphated ECM compared to the other groups. The deposition of AGG, an important ECM protein, is consistent with this observation. In addition, the compression and shear group was the only group where Col 2 immunostaining could be detected. The toluidine blue staining indicates that the sulphated, cartilage-like matrix reaches a depth around 800-900 $\mu \mathrm{m}$. This implies that there may be a form of paracrine signalling occurring between the cells on the upper surface (which experience the shear) and the ones lying in deeper areas of the scaffold. The persistent staining for Col 1 suggests that further optimisation is required. Whether this takes the form of further additional stimulus or a change in hydrogel used to embed the cells needs to be investigated. It has been suggested that platelet-rich fibrin glue is a viable scaffold for implantation of human MSCs into a clinical articular defect (Haleem et al., 2010). However, the small patient group and short (12 months) outcome times means that further investigations are required.

From our results, we can conclude that a combination of shear and compression has superior influence on 
chondrogenesis than either stimulus alone. This would support the theory of applying CPM as post-operative rehabilitation after articular cartilage treatment. Already, the input of a shear force, which is the main input when applying CPM, helps to induce MSCs into a more chondrogenic phenotype - as the gene ratios obtained in this study suggest. In a subsequent study, one can consider extending the loading phase of the constructs, hoping to get more Col 2 signal also on the protein level. A more accurate loading regime may provide better predictions about the behaviour of the cells in an in vivo environment. Therefore, in vitro studies utilising multiaxial load can serve as an intermediate screen between in vitro stages and preclinical animal testing. In particular, we might be able to exclude unsuccessful therapies at an early in vitro stage thus reducing the number of procedures that are later tested in animals. Furthermore, the incorporation of surface shear into the loading protocol might give us some insights regarding CPM procedures used in post-operative rehabilitation after articular cartilage treatments.

Previous studies have demonstrated that a period of preconditioning with TGF $\beta$ followed by uniaxial compression leads to better chondrogenesis than direct application of load in the presence of TGF- $\beta$. This finding together with the data presented here suggest that an initial period of chondrogenic induction, either by growth factor alone or the application of shear superimposed over compression, is required prior to the application of axial load for chondrogenic stimulation. This also suggests that in the natural healing environment (where no exogenous TGF- $\beta$ is present) the initial mechanical environment may play a major role in determining the phenotype of the repair tissue.

During this study we applied the load for $1 \mathrm{~h}$ per day in order to protect the newly forming matrix. It is possible that the duration of load may also play a regulatory role, specifically in the case of osteoblastic markers which did not significantly increase. Any future study on the osteogenic aspects will also include more osteogenic end point analysis, such as ALP protein activity and calcium incorporation. There will also be a large interplay between mechanical stimuli and the growth factors and morphogens, which are also present in the cellular microenvironment. Some of these will be endogenous, so will be derived by the cells experiencing the forces applied

In conclusion, the aim of this study was to investigate if the incorporation of shear in the loading protocol shows a beneficial effect for the progression of MSCs towards a chondrogenic phenotype. The gene expression response is favourable, showing an up-regulation of the chondrogenic markers and unaffected hypertrophic and osteogenic markers with compression and shear. The gene expression data were basically confirmed on the protein level, showing that our loading regime also supports cartilaginous protein expression. However, the persistence of collagen I and the low level of cartilaginous matrix retained within the scaffold means further improvements are required. These data would suggest that shear is a critical component when inducing chondrogenesis in human mesenchymal stem cells by mechanical means. Uniaxial load does not appear to be sufficient under the conditions applied here. This may play a role in natural healing within the musculoskeletal system, whereby the same cell type (MSCs) initiates bone repair (uniaxial load) and cartilage repair (multiaxial load) resulting from different mechanical cues. This knowledge could be used to develop more optimal rehabilitation protocols to be used after implantation of MSCs for cartilage repair.

\section{Acknowledgements}

We would like to thank D. Eglin and M. Glarner (AO Research Institute Davos, AO Foundation, Davos) for producing the polyurethane scaffolds, and Dr Andreas Goessl, Baxter Biosurgery, Vienna, for providing the fibrin components. The authors have no potential conflicts of interest.

\section{References}

Angele P, Yoo JU, Smith C, Mansour J, Jepsen KJ, Nerlich M, Johnstone B (2003) Cyclic hydrostatic pressure enhances the chondrogenic phenotype of human mesenchymal progenitor cells differentiated in vitro. $\mathrm{J}$ Orthop Res 21: 451-457.

Angele P, Schumann D, Angele M, Kinner B, Englert C, Hente R, Fuchtmeier B, Nerlich M, Neumann C, Kujat R (2004) Cyclic, mechanical compression enhances chondrogenesis of mesenchymal progenitor cells in tissue engineering scaffolds. Biorheology 41: 335-346.

Campbell JJ, Lee DA, Bader DL (2006) Dynamic compressive strain influences chondrogenic gene expression in human mesenchymal stem cells. Biorheology 43: 455-470.

Caplan AI (2007) Adult mesenchymal stem cells for tissue engineering versus regenerative medicine. J Cell Physiol 213: 341-347.

Farndale RW, Buttle DJ, Barrett AJ (1986) Improved quantitation and discrimination of sulphated glycosaminoglycans by use of dimethylmethylene blue. Biochim Biophys Acta 883: 173-177.

Gorna K, Gogolewski S (2002) Biodegradable polyurethanes for implants. II. In vitro degradation and calcification of materials from poly( $\varepsilon$-caprolactone)poly(ethylene oxide) diols and various chain extenders. J Biomed Mater Res 60: 592-606.

Grad S, Gogolewski S, Alini M, Wimmer MA (2006a) Effects of simple and complex motion patterns on gene expression of chondrocytes seeded in 3D scaffolds. Tissue Eng 12: 3171-3179.

Grad S, Lee CR, Wimmer MA, Alini M (2006b) Chondrocyte gene expression under applied surface motion. Biorheology 43: 259-269.

Haleem AM, Singergy AA, Sabry D, Atta HM, Rashed LA, Chu CR, El Shewy MT, Azzam A, Abdel Aziz MT (2010) The clinical use of human culture-expanded autologous bone marrow mesenchymal stem cells transplanted on platelet-rich fibrin glue in the treatment of articular cartilage defects: A pilot study and preliminary results. Cartilage 1: 253-261. 
Huang AH, Farrell MJ, Kim M, Mauck RL (2010) Long-term dynamic loading improves the mechanical properties of chondrogenic mesenchymal stem cell-laden hydrogel. Eur Cell Mater 19: 72-85

Huang CY, Hagar KL, Frost LE, Sun Y, Cheung HS (2004) Effects of cyclic compressive loading on chondrogenesis of rabbit bone-marrow derived mesenchymal stem cells. Stem Cells 22: 313-323.

Huang CY, Reuben PM, Cheung HS (2005) Temporal expression patterns and corresponding protein inductions of early responsive genes in rabbit bone marrow-derived mesenchymal stem cells under cyclic compressive loading. Stem Cells 23: 1113-1121.

Kupcsik L, Alini M, Stoddart MJ (2009) Epsilonaminocaproic acid is a useful fibrin degradation inhibitor for cartilage tissue engineering. Tissue Eng Part A 15: 2309-2313.

Kupcsik L, Stoddart MJ, Li Z, Benneker LM, Alini M (2010) Improving chondrogenesis - potential and limitations of SOX9 gene transfer and mechanical stimulation for cartilage tissue engineering. Tissue Eng Part A 16: 1845-1855.

Labarca C, Paigen K (1980) A simple, rapid, and sensitive DNA assay procedure. Anal Biochem 102: $344-$ 352.

Lee CR, Grad S, Gorna K, Gogolewski S, Goessl A, Alini M (2005) Fibrin-polyurethane composites for articular cartilage tissue engineering: a preliminary analysis. Tissue Eng 11: 1562-1573.

Li Z, Kupcsik L, Yao S, Alini M, Stoddart MJ (2009a) Chondrogenesis of human bone marrow mesenchymal stem cells in fibrin-polyurethane composites. Tissue Eng Part A 15: 1729-1737.

Li Z, Kupcsik L, Yao SJ, Alini M, Stoddart MJ (2009b) Mechanical load modulates chondrogenesis of human mesenchymal stem cells through the TGF- $\beta$ pathway. J Cell Mol Med 14: 1338-1346.

Li Z, Yao SJ, Alini M, Stoddart MJ (2009c) Chondrogenesis of human bone marrow mesenchymal stem cells in fibrin-polyurethane composites is modulated by frequency and amplitude of dynamic compression and shear stress. Tissue Eng Part A 15: 1729-1737.

Li Z, Yao SJ, Alini M, Stoddart MJ (2011) The role of retinoic acid receptor inhibitor LE135 on the osteochondral differentiation of human bone marrow mesenchymal stem cells. J Cell Biochem 112: 963-970.

Mauck RL, Yuan X, Tuan RS (2006) Chondrogenic differentiation and functional maturation of bovine mesenchymal stem cells in long-term agarose culture. Osteoarthritis Cartilage 14: 179-189.

Miyanishi K, Trindade MC, Lindsey DP, Beaupre GS, Carter DR, Goodman SB, Schurman DJ, Smith RL (2006a) Effects of hydrostatic pressure and transforming growth factor- $\beta 3$ on adult human mesenchymal stem cell chondrogenesis in vitro. Tissue Eng 12: 1419-1428.

Thorpe SD, Buckley CT, Vinardell T, O’Brien FJ, Campbell VA, Kelly DJ (2008) Dynamic compression can inhibit chondrogenesis of mesenchymal stem cells. Biochem Biophys Res Commun 377: 458-462.

Thorpe SD, Buckley CT, Vinardell T, O'Brien FJ, Campbell VA, Kelly DJ (2010) The response of bone marrow-derived mesenchymal stem cells to dynamic compression following TGF-beta3 induced chondrogenic differentiation. Ann Biomed Eng 38: 2896-2909.

Wagner DR, Lindsey DP, Li KW, Tummala P, Chandran SE, Smith RL, Longaker MT, Carter DR, Beaupre GS (2008) Hydrostatic pressure enhances chondrogenic differentiation of human bone marrow stromal cells in osteochondrogenic medium. Ann Biomed Eng 36: 813-820

Wimmer MA, Grad S, Kaup T, Hanni M, Schneider E, Gogolewski S, Alini M (2004) Tribology approach to the engineering and study of articular cartilage. Tissue Eng 10: $1436-1445$.

\section{Discussion with Reviewers}

Reviewer I: Can the authors speculate on what they believe to be the difference in the cell level mechanical environment between the compression only group, the shear only group and the combined loading group?

Authors: This is a fascinating question. We are trying to determine what mechanical environment would be actually experienced by the cells. The main factor which will decide differences is likely to be what proportion of the shear applied is mechanical shear, and which is fluid shear at the surface. This would also greatly influence how applicable this is to other systems.

Reviewer II: Articular cartilage is physiologically characterised by different layers. Is combined shear and compressive stress the clue to generate cartilage constructs with horizontal alignment of the collagen fibres in superficial zones and vertical alignment in deeper zones? Authors: This is certainly a possibility. In the model system we have so far (Human MSCs) the collagen accumulation is too low to make such conclusions. We know from past studies that bovine chondrocytes produce much more matrix and that would be the ideal cell source to investigate this idea.

Reviewer II: Does shear stress promote the superficial flattened chondrocyte phenotype? and compression stress the larger (hypertrophic) chondrocyte phenotype of deep zones?

Authors: This is a very interesting hypothesis. At the moment we have not looked into cellular phenotype on the differing levels. It would be tempting to speculate this may be the case, but it would require longer term studies, possibly with younger animal cells that produce a more robust response. 